\title{
Study on the Circular Utilization Patterns of City Water Resources
}

\author{
Fang Chen \\ Chongqing Normal University, Chongqing 400700, China \\ 49403591@qq.com
}

Keywords: Water resources, Circular utilization patterns, Sustainable development.

\begin{abstract}
Chinese freshwater resources are rich, but the average amount of water resources per capita is low and water shortage is serious. At the same time, the water population growth, accelerated urbanization process and the traditional extensive model of economic development have aggravated the shortage of city water resources and water pollution. Therefore, studying and constructing the circular utilization patterns of city water resources, which helps to make rational use of city water resources, form a virtuous circle of water resources, and achieve the "zero discharge" of urban sewage and the sustainable development of city water resources, has an important theoretical and practical significance. This paper analyzed the domestic and foreign circular utilization patterns of city water resources on the basis of the status, systematically studied the connotation of circular utilization patterns of city water resources, put forward the mode of sustainable circular utilization of city water resources, and gave the direction of research.
\end{abstract}

\section{Introduction}

City ecological system is an organic whole composed of elements such as, natural environment, social economic environment and political culture, where factors of resources, environment, economy and population interaction with each other, restraint with each other, and support each other, forming a complex artificial ecological system with function of self-regulating, which need to consume lots of resources and energy to keep the system running and discharge all kinds of waste to the system outside. In order to maintain the healthy development of city ecosystem, it is necessary to adjust the system, to change the living habits and production mode, and to control the input and output of the system.

Water is the basic factor of the environment, and the water environment is the most important part of city natural environment ${ }^{[1]}$. Water resources as an important factor in the environment of city resources, directly promote or restrict the development of city social economy. The total amount of water resources in China accounts for $8 \%$ of the total amount of water resources in the world, ranking sixth in the world, however, due to the large population of China, water resources per capita share is about 2200 cubic meters, which is only a quarter of the world average amount per capita, and far below the world average. City water shortage has been very serious these years ${ }^{[2]}$. Anyway, because of unreasonable development and utilization, water pollution, increasing population, accelerated urbanization process and other reasons, our country has already been in the serious crisis of water resources, water resources has become a huge obstacle to the healthy and stable development of the economic society. At present, China's urbanization process continues to accelerate, city scale and city population continues to grow, and contradiction between supply and demand of urban water resource are more acute, water resources have become serious constraint of the smooth realization of the urbanization of our country. To solve the problems of resources shortage and environment pollution brought by the traditional development mode, people begin to find out the drawbacks of the traditional circular utilization patterns of city water resources, and gradually put forward the sustainable circular utilization patterns of city water resources.

We need to make full use of the city water resources from the point view of recycling the city water resources, and attach great importance to the utilization of city wastewater resources. Using the theory of circular economy, the sustainable circular utilization patterns of city water resources can be achieved by improving the use efficiency in minimization, resource, and reusing. The paper will 
discuss the domestic and foreign circular utilization patterns of city water resources, study the circular utilization patterns of city water resources, introduce the sustainable development concept and theory of circular economy, and propose the pattern of sustainable circular utilization of city water resources, from the aspects of principles for overall city water resources planning, development of city water resources, and water resources planning features.

\section{Concept of City Water Cycle}

\subsection{City Water Cycle.}

City water cycle is divided into natural water cycle, artificial water cycle, economic water cycle and social water cycle. Flow chart of city water cycle system is shown in Figure 1.

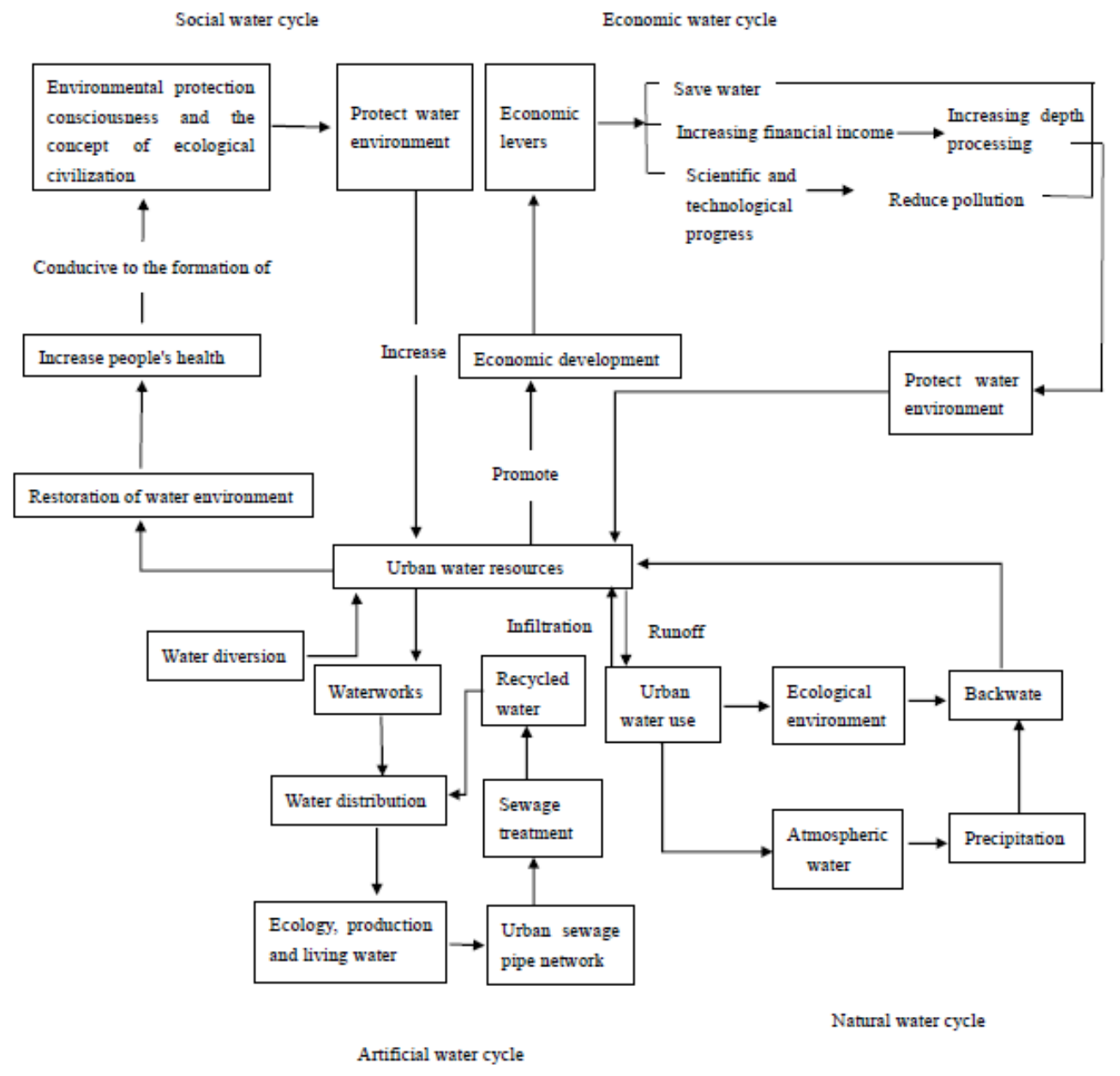

Fig. 1 Flow chart of city water cycle system

Natural water cycle is defined as the city water cycle through evaporation, transpiration, precipitation, surface runoff, soil infiltration and groundwater recharge movement linked with the atmosphere and groundwater ${ }^{[3]}$. Natural water cycle is very important to the recovery of the city water environment and the natural factors in the use of the water cycle are the main consideration.

Artificial water cycle consists of water supply, using, drainage and disposal system of water cycle system. The circular utilization of city water resources can be obtained by using of part of water and producing and treatment of sewage. Part of city water resources comes into water evaporation and part comes into sewage. After treatment of environment and ecological engineering, part of sewage is as reused water resources and part infiltrate into the underground as groundwater resources or become city water resources after precipitation and evaporation process. And remainder discharge into the water, forming city artificial water cycle system. The depth of sewage treatment and use is the main consideration of artificial water cycle in the restoration of water environment ${ }^{[4]}$. 
Social water cycle need to respect the water's natural movement and character, reasonably use water resources, regenerate wastewater after purification, make upstream region of water loop not affect the function water body of downstream water, and promote the restoration and protection of water environment by enhancing people's environmental protection consciousness of water, and then improve city water environment and increase city water resources. Social water cycle is good to water environment restoration and water resources increasing, which can further promote the virtuous cycle and sustainable utilization of water resources. Basically, the formation of social water cycle is conducive to the establishment of artificial water cycle and natural water cycle. Sewage treatment plant is the key to maintain the healthy development of society water cycle, which can purify the city sewage and produce the effect of reclaimed water ${ }^{[5]}$.

Economy water cycle need to take the form of economic lever and the adjustment of industrial structure, standardize the society water amount and promote the progress of water pollution control technology, and save fiscal expenditure and sewage charges by reducing the waste of city water, which can be used for sewage treatment. Thereby it can enhance the natural water cycle, achieve restoration of water environment and increase the city water resources, two of which complement each other to achieve economy water cycle and promote economic sustainable development ${ }^{[5]}$.

\subsection{Study of City Water Resources.}

The quality and quantity of city water resources change with the development of city. The city water consumption is increasing with the development of economic, the adjustment of industrial structure and the application of various water-saving technologies. The research on water environment recycling worldwide is carried out, which can be summarized as follows:

(1)Research of theories and models of city hydrology, including comprehensive management of rainstorm, reuse of waste water, utilization of rainwater, irrigation of farmland, greening of city and supplementary of underground water, etc.

(2)Research of restoration theory of river basin and wetland ecosystem, which mainly studies the mechanism of various aquatic plants on the ecological restoration and ecological balance and ecological risk assessment method.

(3)Study of regional sustainable development of water management evaluation model, including wastewater treatment, drinking water supply, water resources, water resources, water quality and water, etc.

(4)Research of city sewage recycle technology, which focuses on study how to reuse sewage for industrial, miscellaneous water and landscape water of city, add water, agricultural irrigation and city residential area of water, etc.

(5)Research and application of comprehensive utilization technologies of city rainwater collection and coastal city seawater processing. And study of city rainwater mainly focuses on rainwater runoff and savings in the application of city sanitation, fire protection, standby water, green environment, and landscape and groundwater irrigation. Seawater utilization technology mainly includes the seawater desalination, direct use of seawater, seawater chemistry resource utilization and seawater breeding.

The paper will discuss the circular utilization patterns of city water resources and propose the mode of sustainable circular utilization of city water resources, and give the direction of research.

\section{Study on Circular Utilization Patterns of City Water Resources}

The problem of city water resources is increasingly becoming one of the most important issues in the global social and economic development. It is necessary to study the circulation utilization patterns city water resources, and put forward the effective way to solve the problem. The following word will introduce the circulation utilization patterns city water resources, the mode of sustainable circular utilization of city water resources, and give the specific research direction.

\subsection{Circular Utilization Patterns of City Water Resources.}


Individual Circular Utilization Pattern. The single city water unit is the first level of circular utilization patterns of city water resources. Individual water cycle pattern refers to the household water recycling and single enterprise internal water recycling. Household water recycling pattern mainly refers to single family household recycle drinking water and washing water, washing water, kitchen water and flushing watered, as shown in Figure 2.

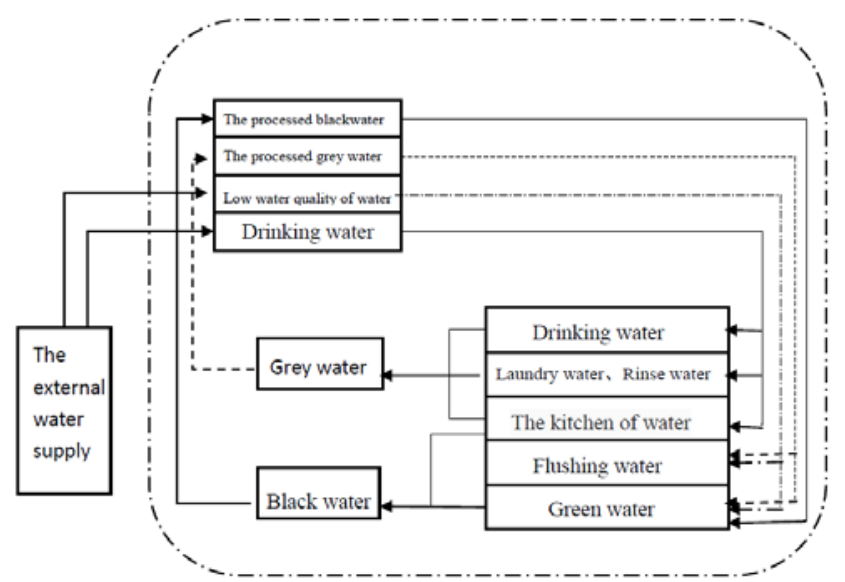

Fig. 2 Household water recycling pattern

Each monomer in production and operation of enterprises in whole process and all aspects need to reduce water consumption and emissions, improve use circulation rate and utilization rate of city water resources, to build a water cycle utilization pattern of "fresh water-industrial water-sewage treatment-a substitute for fresh water" in a single enterprise, from product processing to use, as shown in Figure 3.

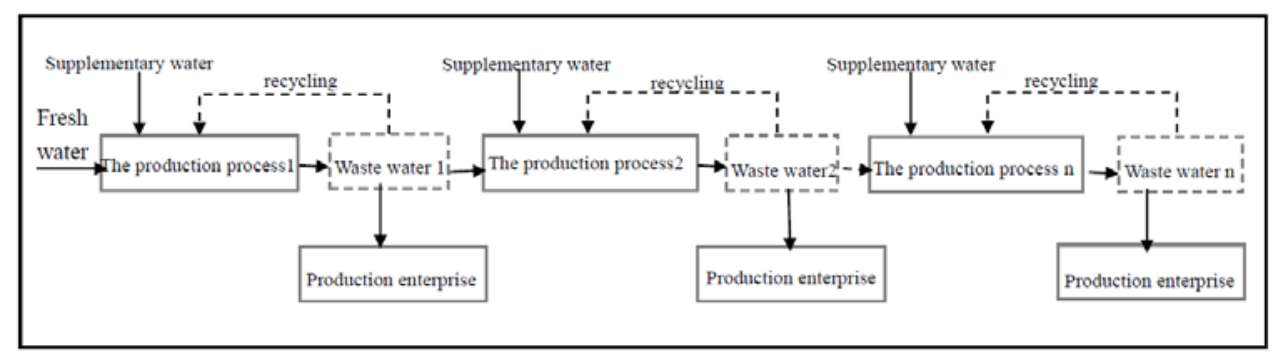

Fig. 3 A single enterprise internal water cycle pattern

Community Circular Utilization Pattern. Enterprise community or residential building communities is a second level of circular utilization patterns of city water resources. Community circular utilization pattern mainly refers to the water circular utilization pattern of ecological residential district and a number of enterprises.

Circular utilization pattern of ecological residential district takes the domestic wastewater (such as, bathing wastewater and washing wastewater, etc.) as the source of water, and domestic wastewater need to go to the outdoor drainage system through indoor collecting and discharging system. After proper treatment, it can be used as general residential water for flushing, landscape water replenishment, green water, road pouring sprinkle water, and sometimes can also further be processed as the car wash water, which can achieve "zero discharge" of residential sewage and make full use of water resources.

Enterprise community refers to similar or related industries of similar enterprises or relevant, which has resource sharing or can form product links of upper, middle and lower reaches of enterprises. Enterprises of association between circular utilization of water resources can build a development platform, complementary exchange, absorption and consumption of water resources, in 
order to jointly promote the recycling and reuse of water resources. The community circular utilization pattern of water recycling inter enterprise group is shown in figure 4.

System Circular Utilization Pattern. System circular utilization pattern is the third level of circular utilization patterns of city water resources. It includes many aspects, such as city sewage reuse, rainwater utilization, etc. System circular utilization pattern of city water resources considerate the city as a co-ordinate system, which builds circulating water using network, to realize system circular utilization of city water resources in agricultural water, industrial water and city miscellaneous water, landscape ecological water. The process of operation of city water system is the input and output process of water resources, which is not only the process of water resources consumption, but also the process of production and discharge of wastewater. At this level, the industry and enterprises need to further expand and extend the more complex link between cities regional water resources closed cycle of recycling use of network. System circular utilization pattern of city water resources is shown in figure 5 .

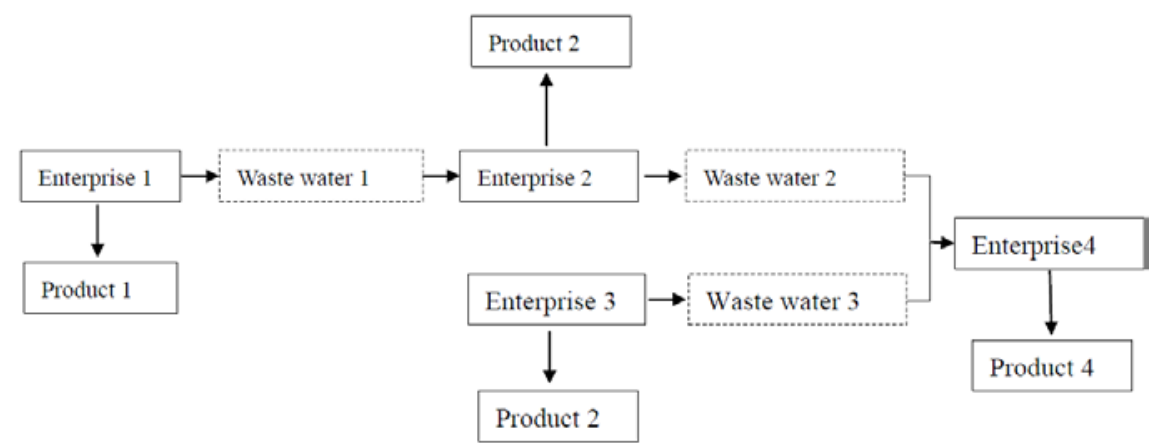

Fig. 4 Community circular utilization pattern

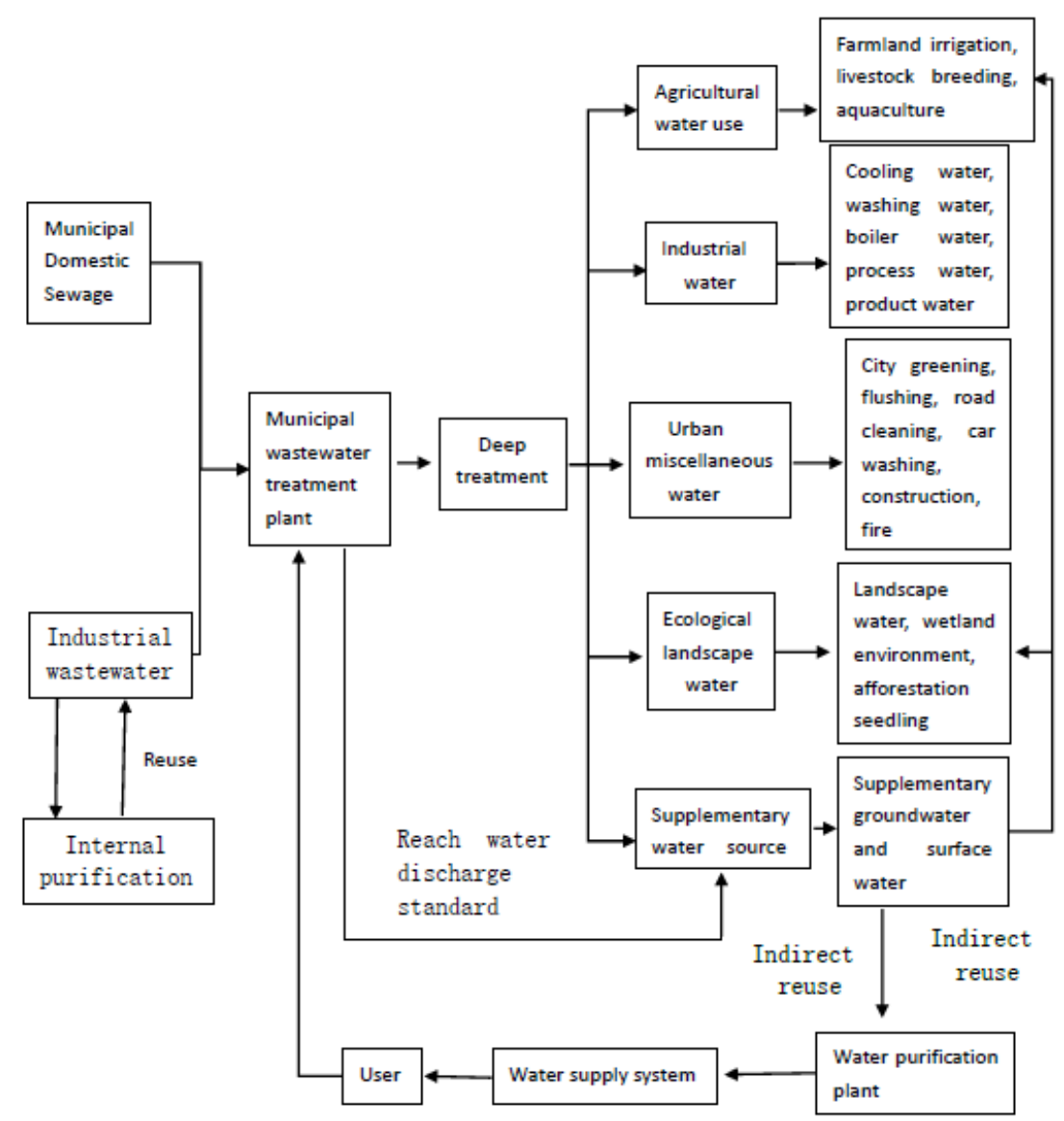

Fig. 5 System circular utilization pattern

\subsection{Sustainable Circular Utilization of City Water Resources.}


Principles for Overall City Water Resources Planning. Natural water cycle is the basis of water resources planning, however, the social cycle of the production and life of human beings affects the value of natural water cycle. Ecocity water resources planning principle indicates that strictly follows the law of the natural water cycle based on the planning of the social water cycle ${ }^{[6]}$.

Development of City Water Resources. Ecocity planning breaks the traditional linear water resources utilization pattern, according to optimal allocation of water quality and quantity. It need to consider the diversified development of available water resources, use reservoir water quality of groundwater for residents living water, replace low water requirements of industrial production water and greening irrigation by reclaimed water or seawater off to add salt water, and make full use of sewage treatment plant for advanced treatment of tail water and conserve rainwater as a city water replenishment. It not only successfully solves the different water unit reliable water supply allocation, but also realizes the development and utilization of the diversification of water resources.

Water Resources Planning Features from Point to Area. Planning of water resources in ecocity also stresses driving the whole city water resource recycling by the module of the area of water resources reuse. For example, each to be developed plots must be given that a certain proportion of permeable paving area and economic rationality of rainwater collection and utilization, and actively seeks small range, which can be called the water resources.

\section{Summary}

The paper firstly introduced the background of the study on the circular utilization patterns of city water resources. And then it discussed the domestic and foreign circular utilization patterns of city water resources, mainly studied the circular utilization patterns of city water resources, and introduced the sustainable development concept and theory of circular economy, and proposed the pattern of sustainable circular utilization of city water resources, from the aspects of principles for overall city water resources planning, development of city water resources, and water resources planning features. The research of the paper is very good for the utilization of city water resources.

\section{References}

[1]. Xu Xiaotong. Thinking of City Water Environment. Journal of Anhui hydropower Vocational Technical College. Vol. 2 (2002) No. 3, p. 1-4.

[2]. Ma Zhongyu and Jiang Hongqiang. On Several Theoretic Issues of Water Recycling Economy and Its Development Measures in China. Journal of China University of Geo sciences (Social Sciences Edition). Vol. 6 (2006) No. 3, p. 21-27.

[3]. Wang Xiuyan, Zhu Tan, Wang Qishan, et al. Analysis to Water Cycle Ways and Its Influence in Cities. Urban Environment \& Urban Ecology. Vol. 16 (2003) No. 4, p. 54-56.

[4]. Cheng Guigeng and Yi Wujun. Urban Compound Water Recycles and Water Environmental Recovery. Journal of Nantong Vocational College. Vol. 17 (2003) No. 4, p. 55-58.

[5]. Zhang Jie and Xiong Biyong. The Implementation Strategy for Urban Healthy Water Cycle. Journal of Beijing University of Technology. Vol. 30 (2004) No. 2, p. 185-189.

[6]. Mao Jianhua, Liu Taixiang, Ma Luyi, et al. Resource saving and environmental friendly technology on soil reclamation for plantings in Sino-Singapore Tianjin Ecocity. Tianjin Agricultural Sciences. Vol. 14 (2008) No. 4, p. 1-3. 